\title{
Contre la méthode, tout contre !
}

Éditorial

Yann Philippe Tastevin et Annabel Vallard

\section{(2) OpenEdition}

Journals

Édition électronique

URL : https://journals.openedition.org/tc/11932

DOI : $10.4000 /$ tc. 11932

ISSN : 1952-420X

Éditeur

Éditions de l'EHESS

\section{Édition imprimée}

Date de publication : 15 juin 2019

Pagination : 6-9

ISBN : 978-2-7132-2786-8

ISSN : 0248-6016

\section{Référence électronique}

Yann Philippe Tastevin et Annabel Vallard, «Contre la méthode, tout contre! », Techniques \& Culture [En ligne], 71 | 2019, mis en ligne le 11 juin 2019, consulté le 29 septembre 2022. URL : http://

journals.openedition.org/tc/11932 ; DOI : https://doi.org/10.4000/tc.11932 
SCMPreng

TIIIN/NI

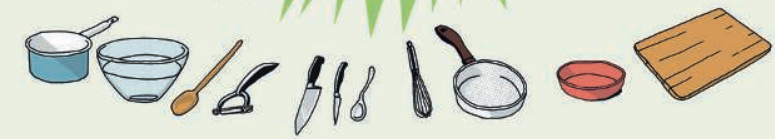

08050 m
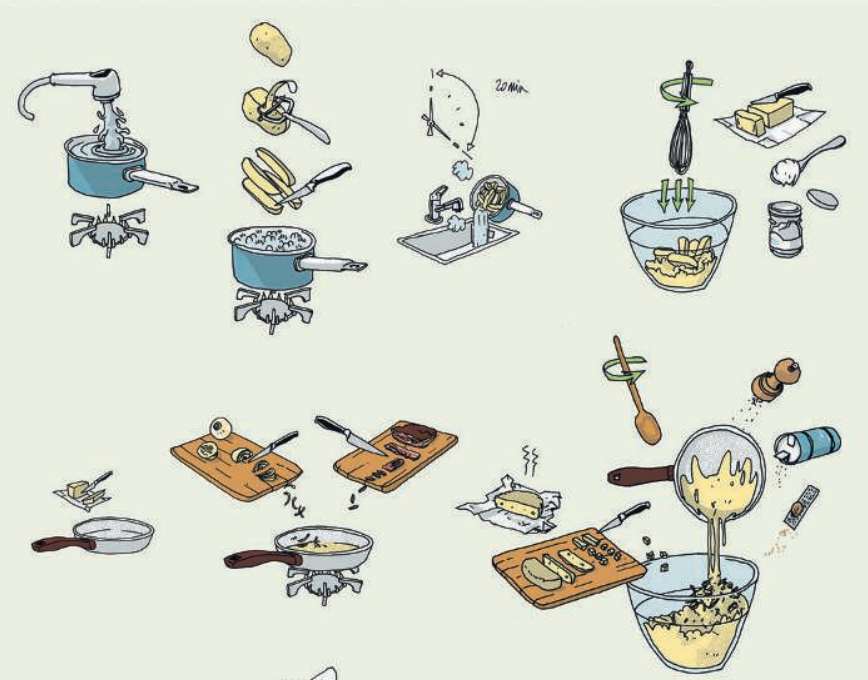

喜 (察如

(0.000)

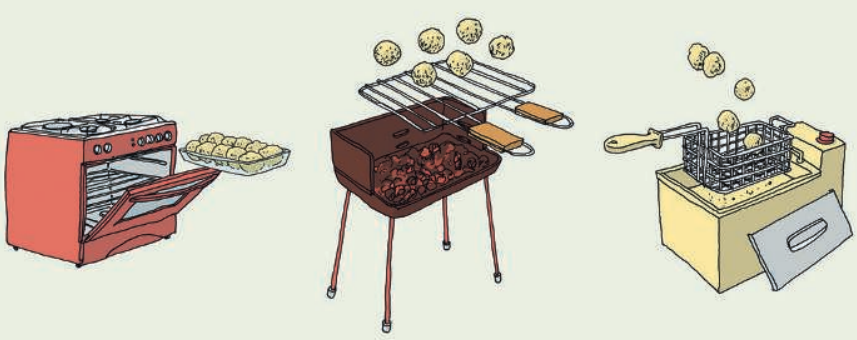




\section{Contre la méthode, tout contre!}

Les «How to », sites collaboratifs et autres recettes de cuisine, ces tutoriels au cœur de la culture Do-It-Yourself(DIY, représentent aujourd'hui le troisième type de contenu le plus regardé sur les plateformes numériques, après l'humour et la musique. La question du «comment... ?» est désormais un critère d'interrogation et un genre à part entière des moteurs de recherche. Et si tout commençait en effet par un «comment»?

Comment «fabriquer une maison pour hamster en bâtonnets de glace »? Comment "protéger ses bretelles» ? Comment «reconnaître l'endroit de l'envers» ? Comment « ouvrir une boîte de conserve sans ouvre-boîtes»? Comment «survivre à l'attaque d'un animal sauvage (requin, mais aussi kangourou)»? Voici que TechniquesE Culture envisage à son tour: comment « documenter ou réanimer des savoir-faire disparus »? Comment «appréhender des processus de création artistique ou la modélisation informatique de procédés de fabrication »? Comment «concilier les façons dont les chercheurs, les praticiens, les fabricants, les ingénieurs, les collectionneurs rendent compte des techniques $»$ ?

TechniquesECulture ouvre ici un espace de dialogue sur les manières de faire et en particulier sur les techniques de collecte, de documentation et d'analyse des techniques: quels sont les outils utilisés par celles et ceux qui travaillent sur les techniques? Indépendamment des objets et des processus, y a-t-il d'autres façons d'« entrer» dans les techniques? Peut-on ou doit-on se passer d'une boîte à outils commune? Si chacun bricole de son côté, comment assurer le comparatisme, enjeu majeur de la technologie culturelle?

Ce numéro Technographies n'inaugure ni un énième traité de méthode-applicable au mieux, par celui ou celle qui le propose-, ni une série de «voilà ce qu'il faut faire», ou de propositions « définitives», mais toute une série d'exemples pratiques au fil des différentes contributions. Ce numéro offre aussi, en bonus, un cahier détachable consacré à un concept et outil phare des technologues: la chaîne opératoire. En préfigurant l'avenir ou en «essuyant les plâtres» 


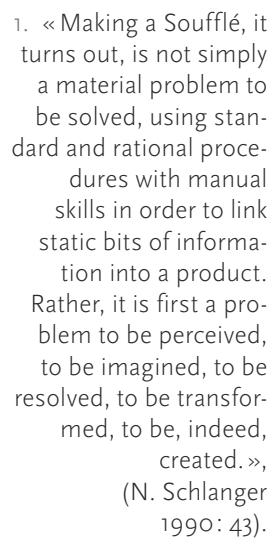
1990: 43).

selon les points de vue, ce supplément est né d'une volonté collective de partage de nos outils de documentation et de représentation des techniques. Autant le dire d'emblée, le Manuel des Castors Juniors inspire davantage ce nouveau chantier éditorial que les Instructions sommaires pour les collecteurs d’objets ethnographiques (Griaule \& Leiris 1931).

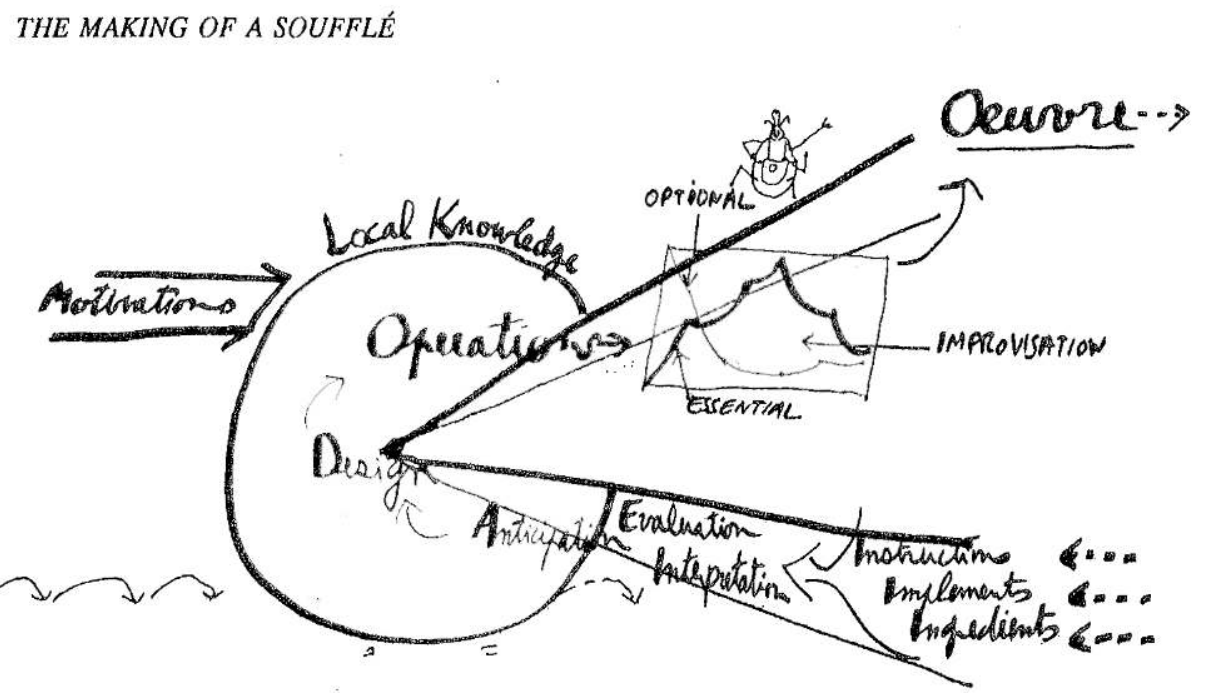

L'objectif de ce nouvel outil documentaire consiste au fil des numéros à venir, à réunir des conseils pratiques pour les néophytes et les collègues qui souhaitent enrichir leur trousse à outils. Ces propositions sont faites par celles et ceux qui ont développé une expérience pratique dans la manipulation des faits techniques, adopté, amélioré et créé des outils spécifiques dans le contexte d'enquêtes de terrain, d'analyse des données, d'archivage ou de valorisation auprès des publics. La forme de ces fiches est libre de ton («il faut», «on pourrait ») et de contenu. Il peut s'agir de textes, de photos, de croquis et dessins ou de leur combinaison. Plutôt que des discours savants, ces fiches apportent des conseils clairs, concis et utiles, susceptibles d'apporter une aide concrète en situation de recherche ou de conservation (ce qui justifie leur format poche et détachable).

Nous ne visons pas l'exhaustivité et rêvons d'un manuel pratique de «technographie» avec ces fiches cumulées comme autant d'expériences partagées. Contre tout méthodologisme, la liste des thèmes et sous-thèmes des méthodes est ouverte, de la description à la représentation 
des milieux, des ambiances, des systèmes techniques, des transmissions... : si votre propre expérience vous permet d'envisager d'autres domaines ou situations dans lesquels des conseils pratiques seraient bienvenus, n'hésitez pas à les proposer. La réflexion sur les méthodes pour inscrire, comprendre et rendre compte des techniques est, à n'en pas douter, un terrain d'entente qu'il faut continuer à arpenter et entretenir, affirment Baptiste Buob, Denis Chevallier et Olivier Gosselain. Espérons qu'elle donne envie et les moyens de mettre les mains dans le cambouis.

\section{Iconographie}

Image d'ouverture. «Schpeckballs - boules de gras», Bastien Massot, illustrateur didactique (batchoubox @gmail.com, batchou.com).

1. Schlanger 1990 : figure 5, p. 45.

\section{Références}

Griaule, M. \& M. Leiris 1931 Instructions sommaires pour les collecteurs d'objets ethnographiques. Paris : Musée d'ethnographie et Mission scientifique Dakar-Djibouti.

Schlanger, N. 1990 «The making of a Soufflé. Practical knowledge and social senses», Techniques\&Culture 15 «Du soufflé à la forge» : 29-52.

\section{Pour citer l'article}

Tastevin, Y.Ph. \& A. Vallard 2019 «Contre la méthode, tout contre!», Techniques\& Culture 71 «Technographies», p. 6-9. 